\title{
MORFOLOGIA URBANA DA CIDADE CONTEMPORÂNEA: Estudo das formas urbanas e dos componentes do Conjunto Habitacional Major Veneziano. Campina Grande, Paraíba. Brasil
}

\author{
Pedro Henrique Vale Carvalho \\ Graduado em Arquitetura e Urbanismo \\ Universidade Federal de Campina Grande - UFCG \\ pedrocarvale@gmail.com
}

\section{RESUMO}

A pesquisa vem sendo realizada pelo grupo de pesquisa Arquitetura e Lugar, vinculado ao curso de Graduação em Arquitetura e Urbanismo/ Universidade Federal de Campina Grande, e está inserida na linha de pesquisa voltada para história e cidade, observando as morfologias urbanas da cidade na contemporaneidade. Possui como objeto de estudo, o Conjunto Habitacional Major Veneziano I, II, III e IV, situados em zona periurbana da cidade de Campina Grande - Paraíba e inserido nas produções habitacionais do Programa Minha Casa, Minha Vida (2009). Trabalha, portanto, o tema da HIS/ Habitação de interesse social investigando a consolidação do conjunto por meio de três variantes - os Sistemas de Espaços Livres intramuros, os condicionantes paisagísticos e a inter-relação da unidade de moradia com os usuários observando as relações existentes e propondo novas análises acerca da produção habitacional inserida nas cidades médias brasileiras.

Palavras-chave: Habitação Social; Morfologia Urbana; Cidades Médias.

\section{ABSTRACT}

The research is being carried out by the research group Architecture and Place, linked to the course of Graduation in Architecture and Urbanism / Federal University of Campina Grande, and is inserted in the line of research focused on history and city, observing the urban morphologies of the city in the contemporaneity. It has as object of study the Housing Complex Major Veneziano I, II, III and IV, located in periurban zone of the city of Campina Grande - Paraíba and inserted in the housing productions of the Minha Casa, Minha Vida (2009) program. Therefore, the HIS / Social Interest Housing theme investigates the consolidation of the complex by means of three variants - the Free Space Systems within the walls, the landscape conditioning factors and the interrelation of the dwelling unit with the users - observing the relationships and proposing new analyzes on the housing production in the Brazilian medium-sized cities.

Keywords: Social Housing; Urban Morphology; Medium Cities. 


\section{INTRODUÇÃO}

Nos últimos anos, muitos pesquisadores têm abordado o tema da habitação de interesse social/ HIS, principalmente, por entender sua influência no crescimento da mancha urbana nas cidades e pelas respostas que podem ser obtidas acerca das relações humanas com o ambiente construído em conjuntos multifamiliares. Porém, poucos olhares estão voltados para a inserção desordenada desses aglomerados nas pequenas e médias cidades brasileiras. Desta forma, a cidade de Campina Grande- localizada no agreste paraibano- por estar inserida em uma zona central de convergência, firma-se como um importante ambiente natural de pesquisa.

A produção do espaço urbano e da habitação vêm sofrendo grandes transformações, seja em âmbito de desenho urbano ou arquitetônico, principalmente quando nos referimos às HIS (Habitações de Interesse Social) e aos programas habitacionais que, ao longo dos anos, tentam suprir uma necessidade quantitativa de moradia, de baixo custo, mas que não deveriam ser de má qualidade.

Ao final dos anos 30, com a intensificação dos processos de urbanização e as iniciais superlotações citadinas, pode-se dizer que o Brasil, pela primeira vez, direcionou seus mecanismos legislativos para a questão habitacional. Tal fato acabou não indicando uma melhora tão significativa já que, mesmo com a criação dos IAPS e da FCP - que podem ser considerados os primeiros programas habitacionais brasileiros - não se pôde observar ainda um grande teor quantitativo, sendo o déficit de moradias após a década de 70 ainda um crescente nacional.

Só com a posterior criação do BNH (Banco Nacional de Habitação) (Figura 1), em 1964, e suas características menos voltadas para o retorno de renda à classe média, que o Brasil iniciou a produção de habitações para a população de baixa renda e trouxe, de fato, um programa habitacional brasileiro funcional e mais direcionado.

Mesmo com uma visão mais quantitativa, e designado a suprir a defasagem habitacional atual, o $\mathrm{BNH}$, como órgão centralizador de ações, não se tornou uma investida do governo suficiente para a causa. Segundo Bonduki (2008), embora a produção edificada do BNH tenha sido significativa, ela esteve muito aquém das necessidades geradas pelo acelerado processo de urbanização que ocorreu no Brasil na segunda metade do século XX. Foram financiadas cerca de $25 \%$ das novas moradias construídas no pais, o que poderia ser considerada uma porcentagem relevante, mas que para a época, não supria o déficit produzido pelo adensamento urbano brasileiro

Dentro dessas possibilidades e posterior a criação do Estatuto das Cidades e do Ministério das Cidades, o Programa Minha Casa Minha Vida foi apresentado como a solução quantitativa que o governo necessitava. Observa-se, entretanto, que mesmo respondendo ao déficit por conta da quantidade de unidades produzidas, o Programa não responde positivamente frente às necessidades de qualidade arquitetônica, urbanística e, muito menos, à qualidade de habitabilidade do espaço edificado.

Os conjuntos apresentam incontáveis dilemas arquitetônicos e urbanísticos que condicionam um crescimento da mancha urbana ainda mais desigual. Identificamos uma arquitetura replicada, com baixa qualidade de inserção urbana, sem arborização, situada às margens da cidade e, muitas vezes, sem infraestruturas básicas para moradia. Uma tipologia habitacional mal dimensionada e projetada sem análises individuais do sítio, onde é possível observar que a segregação socioespacial se encontra cada vez mais presente, tanto em meio urbano quanto em espacialidade das tipologias habitacionais principalmente observadas nas cidade de pequeno e médio porte.

Sanfeliu e Torné (2004) propuseram a classificação de cidade intermediária para as cidades médias, realçando seu papel de articulação ao criar e tecer redes; por introduzir e valorizar aspectos mais dinâmicos e estratégicos que abrem novas possibilidades de inserção urbana nas escalas de cidade. É também nesse meio urbano que a segregação socioespacial encontra-se cada vez mais presente, tanto nas relações entre a cidade formal e informal, quanto em espacialidade das tipologias habitacionais. As barreiras são intensificadas ao passo em que as Habitações de Interesse Social são sinônimos de arquitetura de baixa qualidade e os Programas Habitacionais acentuam ainda mais essa realidade quando postergam o acesso da classe baixa a habitações de qualidade.

Segundo Bonduki (2008:87), "A terra urbanizada, provida de serviços, equipamentos e infraestrutura, tornouse cada vez mais cara, levando os que não tinham recursos a lugares cada vez mais distantes, precários, 
perigosos e à ocupação irregular" e um meio de solucionar ou remediar esses problemas é, para Rolnik e Nakano (2009), lançar mão de pacotes imobiliários que façam uso dos instrumentos previstos no Estatuto das Cidades (2001) que incidam no preço da terra urbanizada, evitando assim a produção de moradias populares para além dos limites da cidade formal.

Além de entender as conformações do espaço urbano para a inserção de conjuntos habitacionais, em discussões acerca das relações entre espaço e usuário, Barros (2008), disserta sobre o que se almeja para um projeto urbano e arquitetônico em habitação, e como as diversas escalas de trabalho podem transformar o espaço, afirmando que é preciso "Abrigar plenamente a relação ambiente-comportamento no projeto da habitação coletiva, o que inclui o resgate de um senso de lugar e de habitar desde a escala da implantação à escala da Unidade Habitacional" (BARROS, 2008:02).

Encontra-se nesse diálogo o cerne para a elaboração deste artigo. As sensações de pertencimento que se expressam a partir da estabilidade dos espaços construídos. O objetivo do artigo é conectar a identidade dos usuários com a qualidade do habitar através da apreensão das dinâmicas presentes dentro das moradias, das realidades impostas pelas soluções projetuais e estratégias de inserção urbana e da estabilidade presente ou não, em conjuntos habitacionais inseridos nas franjas da cidade. Para atingir tal objetivo, foi realizada uma análise com base nas considerações metodológicas propostas por Serra (2006), tomando como estudo de caso, o "Conjunto Major Veneziano composto pelas etapas I, II, III e IV" - como um complexo de objetos arquitetônicos pertencentes a um grande sistema, o qual se configura como um espaço repleto de interações sociais, numa relação de interdependência entre os indivíduos e a cidade.

Portanto, tomando como base a realidade habitacional de Campina Grande e a qualidade construtiva observada nas HIS, percebe-se a necessidade de uma análise mais direcionada aos fatores que condicionam uma melhor habitabilidade do espaço construído, bem como ao funcionamento das dinâmicas entre usuáriodomicílio, edifício-espaço coletivo e conjunto habitacional-cidade.

Partindo da problemática e dos questionamentos anteriormente referidos, a pesquisa apresenta natureza qualitativa, propondo-se a entender a realidade construtiva e social das HIS, por meio da coleta, análise e comparação de dados obtidos, tendo sua metodologia baseada nas conceituações propostas por Serra (2006) para definir processos e sistemas. Por processo, se entende "o modo como se sucedem os estados diferentes do sistema no tempo" e por sistemas "um conjunto de objetos entendidos como uma totalidade de eventos, pessoas ou ideias que interagem uns com os outros" (SERRA, 2006:70-72).

Os procedimentos metodológicos realizados levaram em consideração as inter-relações entre o sistema e seu entorno, bem como os processos ocorridos entre os objetos e o sistema com aplicações de caráter mais analítico e descritivo. Para tanto, foram realizados procedimentos, a saber: a) registros fotográficos; b) visitas in loco; c) aplicação de fichas de observação nos conjuntos e unidades de habitação; Tais procedimentos visam inserir e analisar o objeto de estudo em um contexto de Unidade de Vizinhança, direcionado para o objetivo do artigo e capaz de proporcionar uma visual mais ampla das instabilidades que rodeiam a produção da habitação e do espaço urbano nas cidades brasileiras.

\section{INTERAÇÕES MORFOLÓGICAS: CIDADE E CONJUNTO HABITACIONAL}

A cidade de Campina Grande, situada no Planalto da Borborema, encontra-se a aproximadamente $150 \mathrm{~km}$ da capital João Pessoa. Devido à proximidade com importantes centros comercias da região nordeste, à exemplo de Recife-PE e Natal-RN, consagrou-se como um grande polo agroexportador de algodão e, atualmente, como um polo tecnológico de referência mundial. Tais características incitaram um acentuado processo migratório - hoje denominado de mobilidade populacional - advindas principalmente do Agreste Paraibano e que, segundo estudos realizados por Melo (1997) e Silva (1986), configura-se como um importante agente causador do intenso processo de favelização e espraiamento das cidades contemporâneas. 


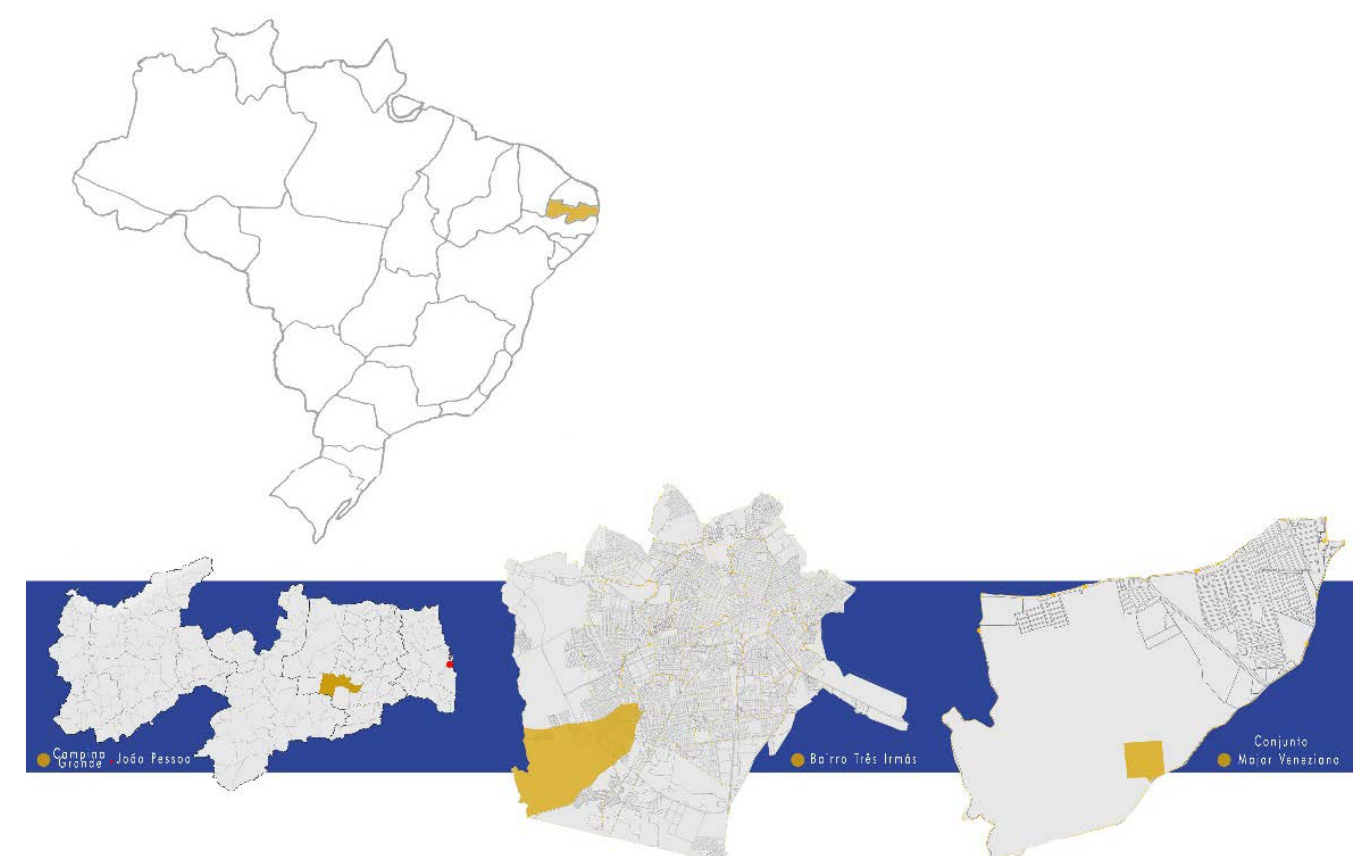

Objeto de Estudo - Conjunto Major Veneziano e a Cidade de Campina Grande (Carvalho, 2017) Elaboração própria

Topalov (1997:40) reitera essas tendências de crescimento ao indicar transformações ocorridas, principalmente na década de 90, nos aglomerados urbanos: i) intensificação das relações intrametropolitanas, indicando uma maior independência das cidades intermediárias para com os grandes centros; ii) a inserção dos debates de cunho ambiental, incorporados agora nas discussões sociais; e iii) a valorização das relações mercadológicas através de uma redefinição do papel econômico do Estado nas dinâmicas urbanas.

Existe assim, uma aproximação ou sobreposição do meio urbano com o meio rural, uma expansão morfologicamente espraiada e concretizada principalmente a partir da construção das vilas operárias, dos bairros industriais e, posteriormente, com a inserção dos grandes conjunto habitacionais fomentados pelos programas governamentais de desenvolvimento. Conjuntos esses que adensam terras localizadas nas franjas da cidade e que ainda não apresentam infraestrutura adequada ao imprimirem novos processos de periferização da cidade.

A construção do Complexo Habitacional Major Veneziano, finalizada em 2013, provocou mudanças na lógica urbana da cidade principalmente no âmbito da mobilidade urbana e na disponibilidade e distribuição de equipamentos urbanos, além de incrementar os processos de higienização nas cidades e dificultar ainda mais a mistura social nos bairros mais estruturados.

De acordo com o Plano Diretor de Campina Grande (2006), a implantação do Residencial (I, II III e IV) se desenvolveu na Zona de Expansão Urbana prevista pelo Plano (CAMPINA GRANDE, Lei Complementar 033/2006), "onde o uso e a ocupação do solo destinam-se ao crescimento da cidade." Associado a essas definições do Plano Diretor para as áreas de expansão, soma-se ainda fatores importantes como a baixa especulação imobiliária, baixo preço da terra ainda não urbanizada e a tentativa de evitar a mistura urbana, fator esse que garante vitalidade urbana e qualidade de moradia para a sociedade.

Levando em consideração as dimensões do referido conjunto, o impacto ambiental e urbano causado acaba sendo de grandes proporções principalmente por estar inserido distante da cidade formal. Promove-se um deslocamento de eixo populacional, percebido principalmente através da visível necessidade desses novos moradores em frequentar espaços que respondam às suas atividades diárias, como postos de saúde, supermercados, bancos, lotéricas, etc. Os bairros adjacentes não conseguem suprir esse déficit, causado grande influência nas dinâmicas urbanas das unidades de vizinhança já consolidadas.

Neste caso, os bairros Acácio Figueiredo e Malvinas, que apresentam relativa independência, tem seus equipamentos urbanos, como postos de saúde, escolas e creches, sobrecarregados pela população dos novos empreendimentos de habitação. 


\section{O CONJUNTO HABITACIONAL COMO UNIDADE DE VIZINHANÇA}

Conceitos iniciais propostos por Clarence Arthur Perry, no século $X X$, presentes também nos estudos de Barcellos (2001) e Oliveira (2006) definem Unidades de Vizinhança como uma área residencial que apresenta pertinente autonomia quando conectada às necessidades básicas cotidianas de consumo de bens e utilização de equipamentos urbanos, mas que precisam estar conectadas aos centros urbanos numa relação de equilíbrio coletivo e mistura social.

Fazendo uma análise acerca da complexidade de inserção urbana dos Conjuntos e visualizando esse montante como um heterogêneo grupo numérico, observa-se que, devido à grande quantidade de unidades de moradia - 1.984 unidades no caso do Major Veneziano - é possível criar um paralelo entre as definições qualitativas de Unidade de Vizinhança e a produção das HIS na atualidade, tanto em planejamento urbano quanto em soluções espaciais.

Segundo Oliveira (2006), para o seu desenvolvimento e consolidação, a UV depende de seis fatores primordiais. $\mathrm{O}$ "dimensionamento" precisa ser realizado com base nas demandas populacionais requeridas pelas escolas elementares. O "limite" de uma UV devem ser materializados por ruas bem dimensionadas que facilitem o tráfego veicular, peatonal e a conexão no território, evitando assim sobreposições de fluxos. Os "espaços públicos" devem funcionar como um sistema de espaços livres de permanência e recreação, composto por pequenos parques e zonas de encontro e interações comunitárias.

As "áreas institucionais", em um nível de planejamento regional, devem coincidir com os limites da UV, adequadamente agrupadas em um lugar central, comum e espacialmente adequadas as demandas da Unidade e dos sistemas preexistentes. O "comércio local" deve ser disposto em um ou mais locais próximos aos usuários e devem estar situados, de preferência, junto as principais vias adjacentes ou de outras Unidades de Vizinhança. Por fim, não menos importante, o "sistema viário" conforma-se como um facilitador da circulação interna, delimita os acessos veiculares e de pedestres conectando as unidades habitacionais com os espaços livres e as preexistentes zonais urbanas.

Ao inserir uma grande unidade de vizinhança sem as devida preexistência de equipamentos urbanos, tornase quase impossível prever uma estabilidade urbana positiva para aquele ambiente. No Major Veneziano estavam previstas a construção de escolas, creches, comércios locais e posto de saúde, mas, como esperado, até o dado momento nada foi construído. Essa indisponibilidade impossibilita o total enquadramento do residencial nas características que definem uma estável unidade de vizinhança.

Todos esses fatores são facilmente aplicados na elaboração, implantação e avaliação dos conjuntos habitacionais produzidos na atualidade. A presença ou não de alguns deles sugere um distanciamento entre o ambiente construído e conceitos humanizadores na produção de moradia e das unidades de vizinhança e a partir dessa comparação é possível verificar a interdependência entre as estratégias de inserção urbana, o processo de projeto arquitetônico e os condicionantes ambientais e paisagísticos. A consolidação dos conjuntos habitacionais.

\section{INTRAMUROS: SITUAÇÃO E APROPRIAÇÃO}

Após a realização de visitas, registros fotográficos e analises intramuros foi possível averiguar a estabilidade do Conjunto Major Veneziano sob três pontos de vista - os Sistemas de Espaços Livres intramuros, os condicionantes paisagísticos e a inter-relação da unidade de moradia com as configurações familiares existentes.

Os Condomínios Residenciais Major Veneziano I, II, III e IV foram construídos dentro dos parâmetros do Programa Minha Casa Minha Vida 2 e, constituindo um grande complexo habitacional, aglomeram cento e vinte e quatro blocos com Planta $\mathrm{H}$, circulação central e dezesseis apartamentos por edifício, totalizando cerca de 1.984 unidades padronizadas de habitação. Seu entorno é composto basicamente por vazios urbanos sem predisposição a ocupação e sem projeto futuros de apropriação.

Esses vazios urbanos desconectam o lote dos demais parcelamentos urbanos e se configuram como um limite de difícil transposição. Além desse isolamento territorial, os conjuntos encontram-se delimitados por muros, o que dificulta ainda mais a permeabilidade cidade-moradia que tanto se almeja para aglomerados habitacionais desse porte. 


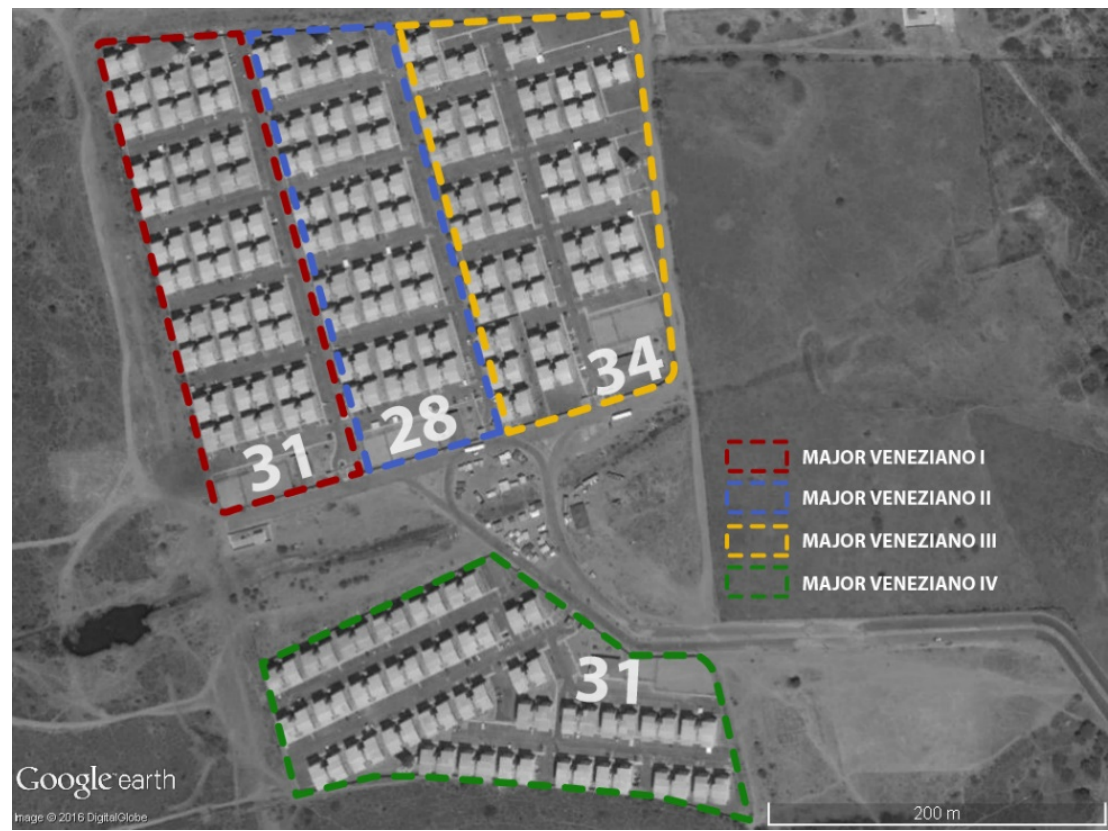

O Conjunto Major Veneziano_Configuração

(Carvalho, 2017) Elaboração própria a partir base Google Earth

Priorizando a lógica do automóvel, em detrimento a dos pedestres, o conjunto possui fluxos e acessos simplificados, com suas vias principais distribuídas ortogonalmente no terreno, facilitando o acesso por carros e motocicletas. Proporciona, desta forma, longas caminhadas aos transeuntes que, em sua maioria, não possuem outras formas de locomoção. Devido a esta lógica de implantação, possui apenas um acesso principal, responsável pelo controle de entrada e saída. Importante salientar que, os últimos blocos de apartamentos se encontram a quase $300 \mathrm{~m}$ deste acesso, concretizando assim uma implantação que não valoriza quesitos de acessibilidade e distâncias mínimas a serem percorridas.

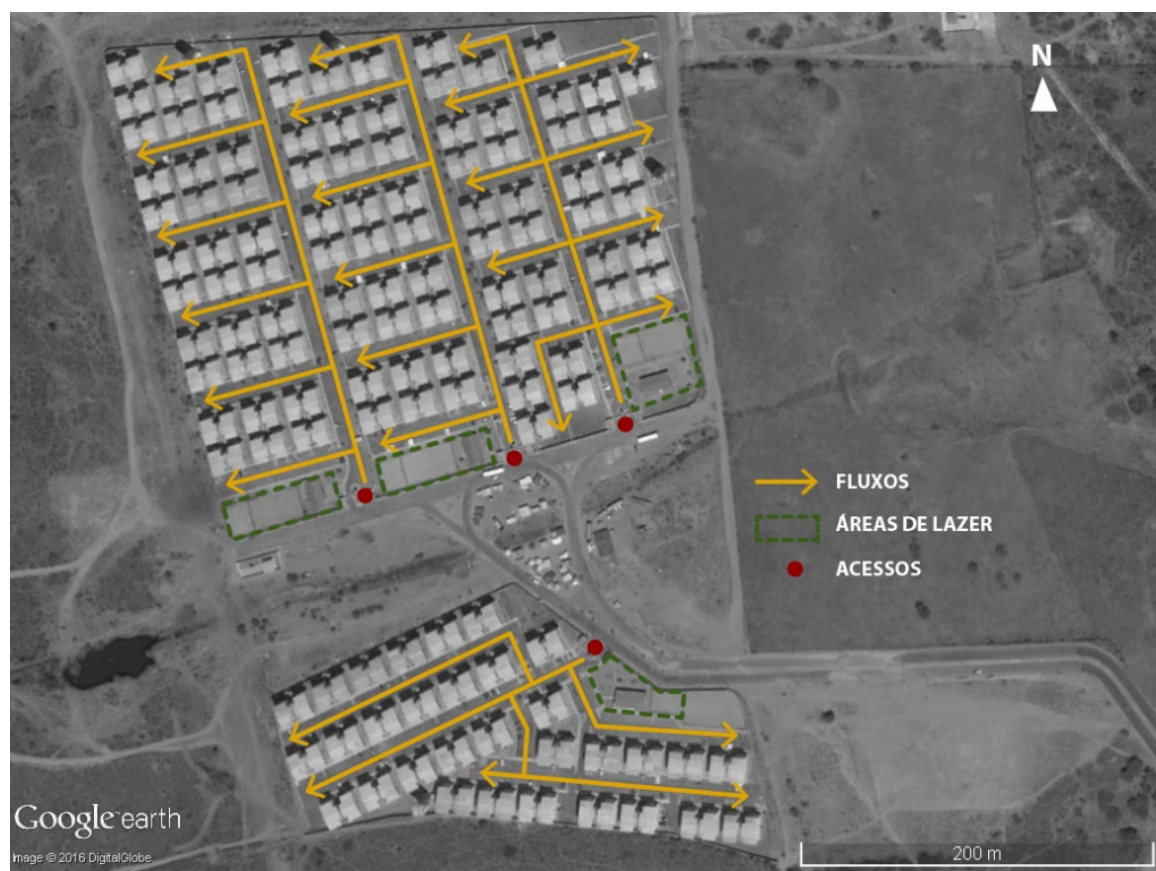

\section{O Conjunto Major Veneziano_Fluxos}

(Carvalho, 2017) Elaboração própria a partir base Google Earth

Ocorre, nessa situação, uma sobreposição entre os fluxos existentes que acaba impossibilitando a ocupação dos espaços livres e a interação social. O dimensionamento das calçadas compromete o acesso peatonal ao conjunto, reduzindo o nível de caminhabilidade em toda a sua extensão ao ceder espaço para a inserção dos estacionamentos. Para Ghidini (2010), a caminhabilidade pode estar associada aos outros meios de 
transporte, a exemplo das bicicletas e do próprio automóvel, mas para essa estabilidade é necessário que a velocidade seja comum em todos e que o caminhar do pedestre seja privilegiado.

O mesmo problema ocorre quanto à disposição das áreas de permanência. Essas zonas, que se encontram na região frontal dos conjuntos, são compostas por quadras poliesportivas, playgrounds e salões de festas que, por estarem distantes de muitas residências, são subutilizados. Esses espaços também não apresentam uma arborização adequada para seu uso e a consequente inexistência de sombras impede que, em determinados horários, a zona destinada ao lazer possa vir a ser utilizada pelos moradores. Decorrente disto, é comum em períodos mais ensolarados - sol poente das $14 \mathrm{~h}$ às $16 \mathrm{~h}$ - o lugar mais utilizado serem as sombras projetadas pelos próprios edifícios.

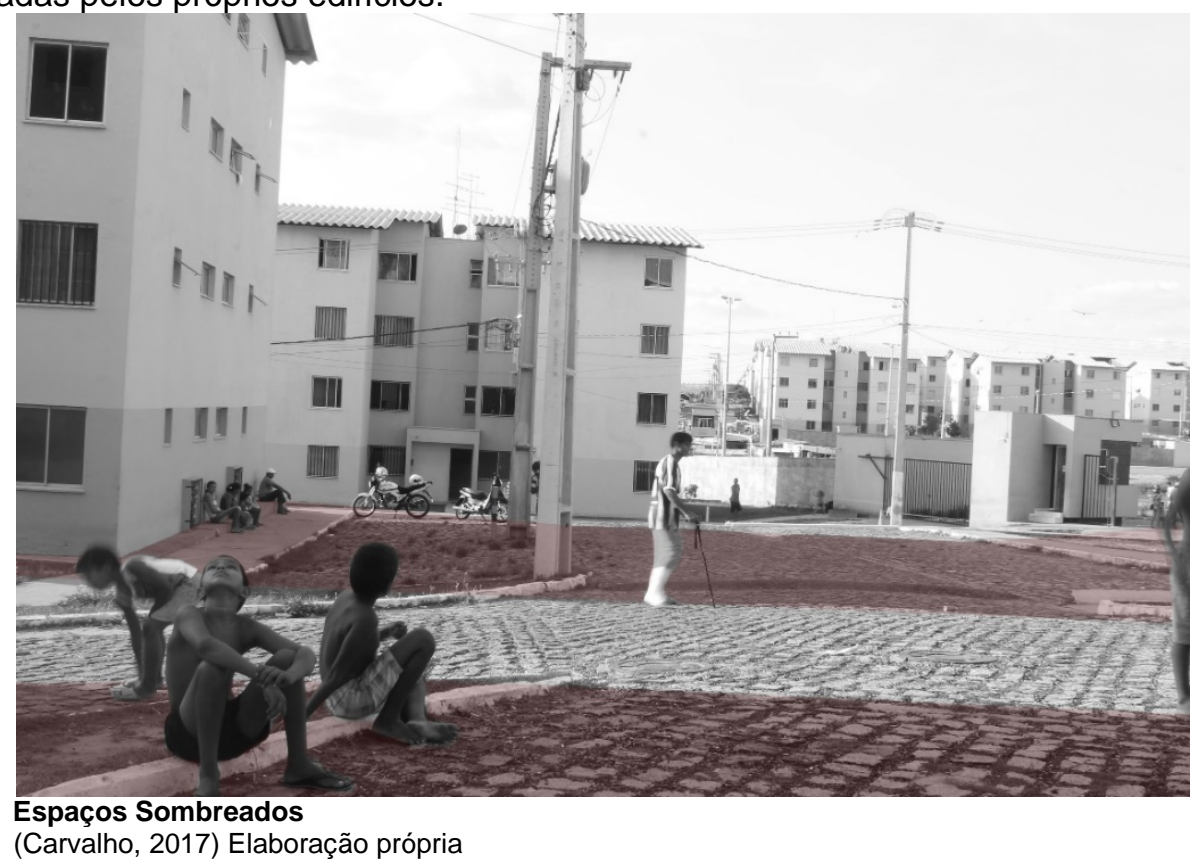

A criação de um sistema de espaços livres, observado como fator determinante na consolidação das UV, promove a estabilidade dos fluxos existentes em um sistema de compartilhamento usuário-meios de transporte e insere respiros em regiões densamente construídas, conectando as áreas de permanência com os edifícios, sempre lembrando que a permeabilidade de um conjunto não está apernas associada aos espaços vazios/livres, mas também ao diferentes usos e funções que cada ambiente tem dentro de um sistema. Neste caso, o zoneamento tem a função de costurar esse espaço urbano intramuros conectando a individualidade do morar com a coletividade dos espaços de interação social.

Um planejamento paisagístico eficaz promove uso mais livre dos espaços de lazer, garante conforto ambiental positivo e pode gerar movimentação de usuários em zonas mais distantes das primariamente definidas como áreas de convivência. Os espaços entre os blocos residenciais ou até mesmo as quadras ainda não utilizadas, caso sombreados, tornam-se disponíveis para apropriação, evitam sobrecarga no único setor destinado ao lazer e facilita o acesso para os moradores.

No caso do Major Veneziano e do Bairro do Três Irmãs é comum observar a inexistência dessa massa arbórea. Temos então espaços muito ensolarados, com pouco uso durante o dia e com uma condição estética precária. A falta de planejamento paisagístico provoca monotonia nos espaços livres e reitera a não conexão entre as diversas instancias do projeto. Para visualizar tal características foi usado a manipulação digital para simular o mesmo ambiente em uma situação de paisagismo eficiente.

Com isso, observa-se a importância das sombras para as dinâmicas sociais nas escalas de projeto urbana a fim de garantir interações sociais em diferentes turnos, boa absorção das águas das chuvas e usos mais lúdicos dentro dos conjuntos. 

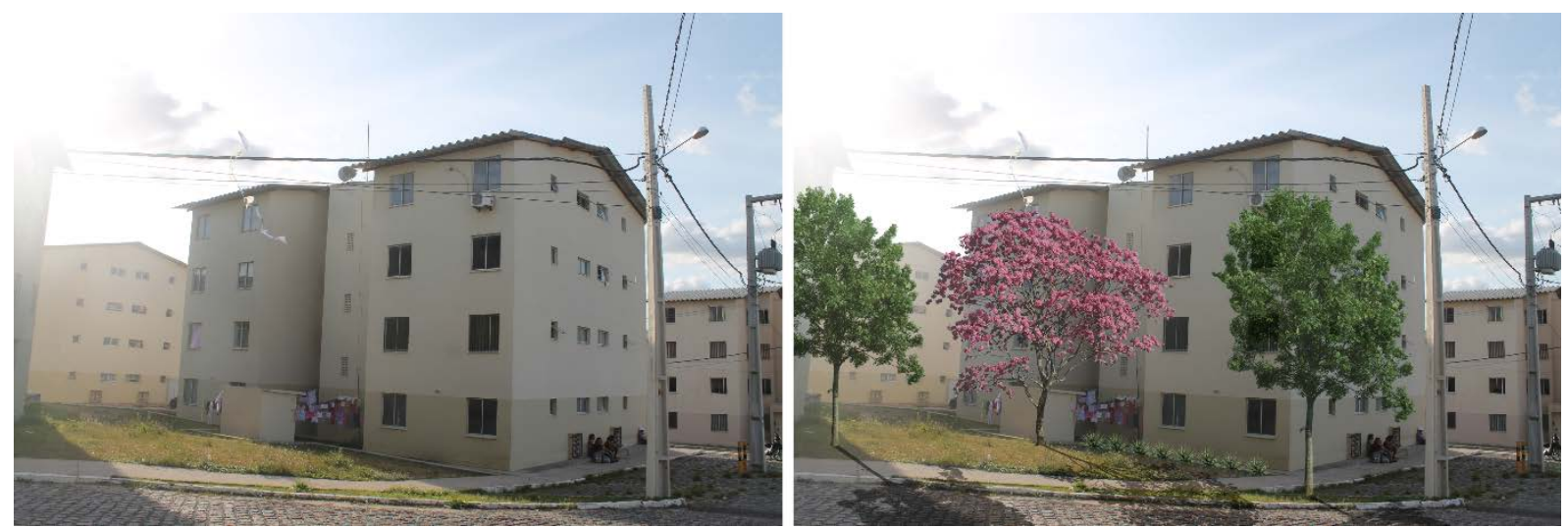

Sistemas de Espaços Livres (SEL)

(Carvalho, 2017) Elaboração própria

Outro objeto que se faz muito presente nas cenas observadas são os varais. Em janelas, muros ou até casas de motor, os varais são uma resposta visual à inexistência de espaços de serviço capazes de suprir essa necessidade, seja por falta de ventilação, dimensionamento adequado ou insolação direta.

Esta apropriação espontânea sugere, além da ineficácia das soluções projetuais, uma sensação de pertencimentos dos moradores para com o ambiente residencial. Existe uma liberdade dos moradores em fazer uso do conjunto em que residem para suprir suas necessidades mais funcionais e de logística. As fachadas acabam se tornando espaços externos anexos à própria unidade habitacional.

Esta características talvez esteja associada também ao costume advindo das casas térreas e soltas no lote em que a maioria desses moradores residia. Levando em consideração que muitos ocupavam os bairros mais povoados da cidade, é comum a extensão desses costumes das residências unifamiliares para as multifamiliares.
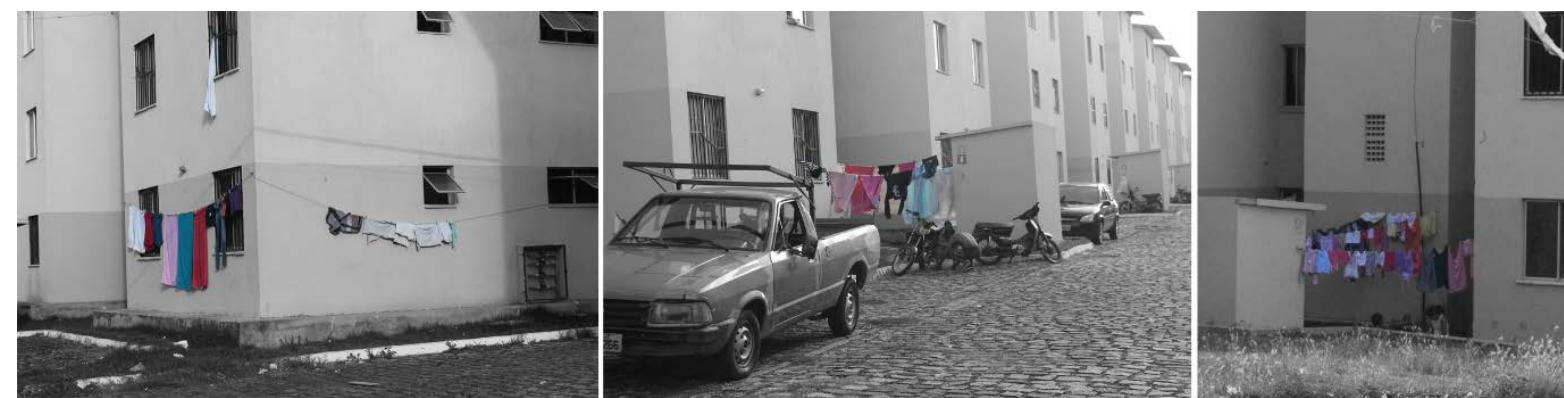

Apropriação espontânea (Os varais)

(Carvalho, 2017) Elaboração própria

Individualizando um pouco mais as análises, o próximo tópico incorpora às configurações de cidade e ao projeto de loteamento as interações sociais ocorridas dentro das unidades de habitação, permitindo assim a associação, sobreposição ou concomitância de lógicas urbanas, projetuais e comportamentais.

\section{AS RELAÇÕES MORADOR-MORADIA}

Para maior apreensão das apropriações realizadas pelos moradores com as unidade habitacionais, fichas de observação foram aplicadas em oitenta apartamentos - vinte em cada conjunto - analisando pontos relacionados à consolidação e compatibilidade dos cômodos, conforto ambiental, espaços de acesso (Hall), bem como a relação entre as configurações familiares e o dimensionamento das unidades habitacionais. Obteve-se, como produto, infográficos que geram análises projetuais importantes para a inserção de novas tipologias de habitações sociais em Campina Grande e cidades que apresentam morfologias urbanas similares.

O primeiro ponto observado foram as composições familiares levando em consideração a influência da quantidade de moradores na experiência de moradia e que, neste caso, se constituíram bastante heterogêneas principalmente quando relacionadas com a única tipologia de moradia disponível. Encontra-se desde idosos aposentados morando sozinhos até famílias compostas por oito integrantes, demonstrando a rigidez da tipologia e sua inadequação aos grupos familiares existentes. 


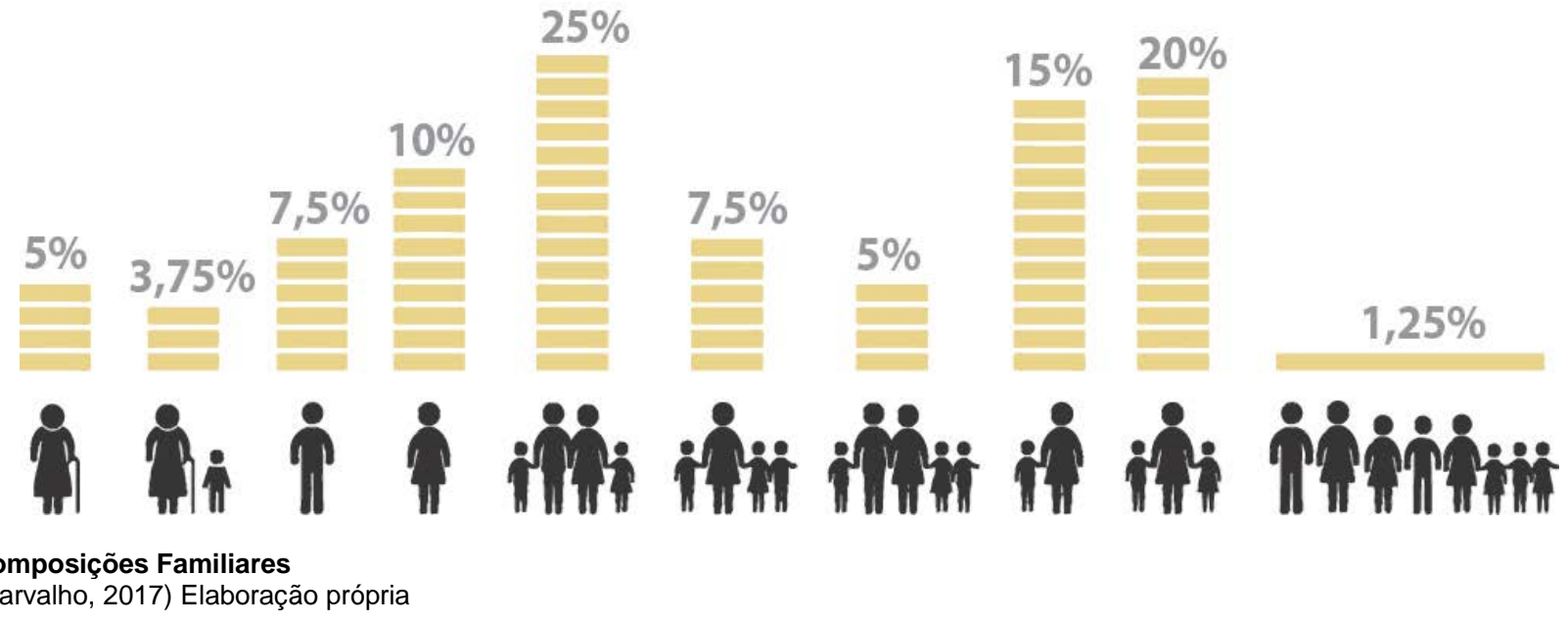

O próximo elemento a ser observado está relacionado à consolidação dos cômodos, entendendo como mais consolidados aqueles espaços que apresentam mobília adequada, tratamentos arquitetônicos ou estéticos como pintura, texturas, revestimentos, móveis projetados, entre outros. Em suma, os espaços em que o morador demonstra ter mais apego ou uso, cômodos que fazem mais parte da sua rotina diária e das suas dinâmicas de moradia.

No Conjunto Major Veneziano, observa-se que 56,25\% das residências tinham a sala de estar/jantar como o espaço mais consolidado, seguido dos quartos $(21,25 \%)$ e a cozinha (10\%). Tal porcentagem provavelmente se deve a uma lógica que prioriza os espaços de uso mais coletivo em detrimento dos espaços mais íntimos.

\section{QUAIS CÔMODOS PARECEM ESTAR MAIS CONSOLIDADOS?}

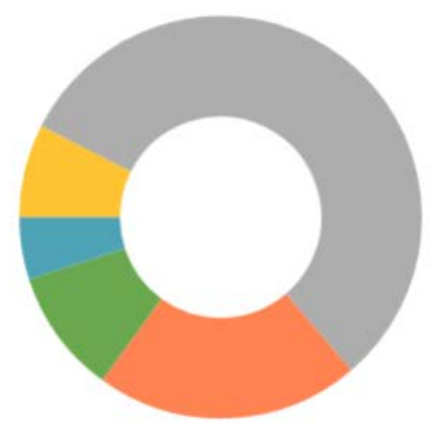

\section{TODOS $(7.50 \%)$ SALA $(56.25 \%)$ QUARTO $(21.25 \%)$}

COZINHA (10.00\%) BANHEIRO $(5.00 \%)$

\section{Consolidação dos Cômodos}

(Carvalho, 2017) Elaboração própria

O gráfico e sua análise possibilita o entendimento da conexão entre a conformação espacial e as lógicas de apropriação da unidade habitacional, através da materialidade do espaço ocupado por móveis, intervenções arquitetônicas e de design, bem como do sentimento de pertencimento do usuário para com a habitação, fator de grande importância para obter informações acerca dos níveis de apropriação nas relações moradormoradia. 
Acredita-se que devido ao maior contato dos usuários com a sala de estar/jantar, principalmente por ser o cômodo de maior interação social dentro de um ambiente residencial e também o "cartão de visita" da família, a sala foi observada como o espaço mais consolidado das unidades habitacionais. Indica-se, desta forma, uma maior apropriação e sentimento de pertencimento dos moradores neste ambiente. Gradativamente e relacionado com o menor índice de interação social, os cômodos considerados mais íntimos se apresentam menos consolidados e, por consequência, menos representativos para os usuários.

O próximo ponto observado foi a incompatibilidade de usos dentro dos cômodos partindo do pressuposto de que o mal dimensionamento das unidades acaba por obrigar os usuários a combinar diferentes usos em um mesmo espaço. As necessidades diárias acabam indo além da rígida conformação adotada pelo projeto MCMV, estando totalmente associado ao desequilíbrio entre o contingente familiar e a oferta de tipologias em um mesmo conjunto.

Devido à ineficiência das áreas de serviço, foi corriqueira a presença de varais improvisados em diversos ambientes dos domicílios - a exemplo da sala e do segundo quarto - assim como adaptações dos quartos como espaços de trabalho para complementação de renda, reflexo da necessidade dos usos mistos nas habitações de interesse social.

\section{POSSUI USOS INCOMPATÍVEIS?}

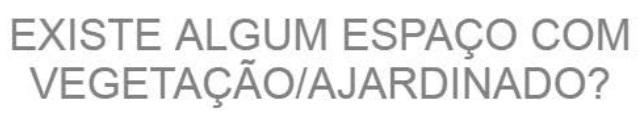

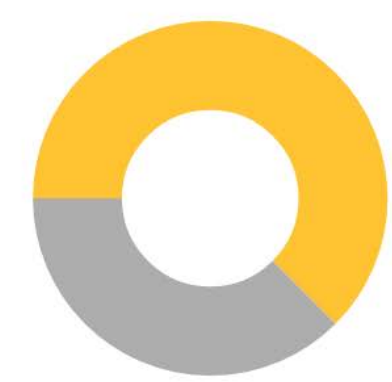

NÃO $(62.50 \%)$

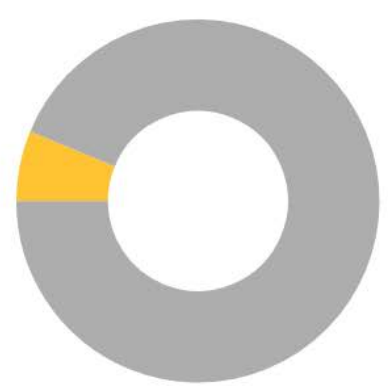

$\operatorname{SIM}(6.25 \%)$ NÃO $(93.75 \%)$

Usos Incompatíveis e Espaços Ajardinados

(Carvalho, 2017) Elaboração própria

A relação entre o espaço urbano e a habitação pode ser consolidada de diversas formas, principalmente através da inserção de zonas verdes que conectam os espaços internos com os externos. Neste caso, decorrente da falta de paisagismo nas zonas externas, observar esses elementos internamente pode refletir uma necessidade dos usuários por espaços ajardinados, zonas sombreadas e elementos paisagísticos. De acordo com o Gráfico, apenas 6,25\% dos domicílios apresentam algum elemento paisagístico, mas ao observar a entrada dos edifícios, a presença de jardins elaborados pelos próprios moradores corrobora com a deficiência paisagística visível dos Conjunto Major Veneziano.

Como as afirmações de Topalov (1997), é importante a inserção dos debates de sustentabilidade ambiental conectado às analises socioespaciais tanto de moradia quanto de planejamento urbano. Esse debate trabalha a favor da melhor qualidade de cidade e de moradia dentro das pequenas, médias e grades cidades brasileiras.

Também ligado às relações de apropriação do espaço construído pelos usuários, os Halls de acesso aos domicílios sofrem pequenas modificações que indicam relações de pertencimento ou até mesmo um déficit de espaços apropriados para interações sociais. Decorrente da inadequada implantação do conjunto ou desigual inserção dos espaços coletivos, $35 \%$ dos pavimentos visitados apresentavam pequenas mudanças em seus halls de acesso. Presença de jarros, novas pinturas e até mesmo móveis criavam novos espaços de permanência dentro dos edifícios. 
Os níveis de ambiência foram analisados a partir da presença ou não de mecanismos de conforto ligados durante a aplicação da ficha, constatando assim que 15\% dos domicílios tinham ventiladores ou lâmpadas ligadas. Interessante perceber que boa parte dessas residências se encontrava nos últimos blocos do conjunto, constatando mais uma vez que a inserção do conjunto com edifícios paralelos prejudica a insolação e ventilação.

\section{MECANISMOS DE CONFORTO COMO SE COMPORTA OS ESPACCOS ENCONTRAM-SE LIGADOS? DE ACESSO ÀS HABITAÇÕES?}

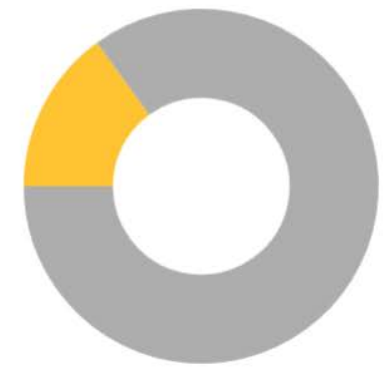

$\operatorname{SIM}(15.00 \%)$ NÃO $(85.00 \%)$

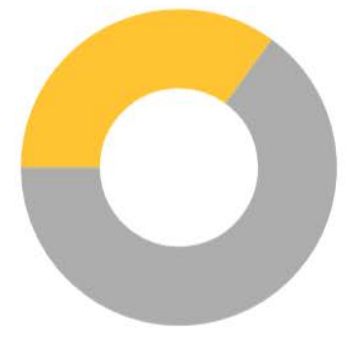

POUCO MODIFICADO (35.00\%) NÃO SOFREU ALTERAÇÕES (65.00\%)

Conforto Ambiental e a Consolidação dos Halls

(Carvalho, 2017) Elaboração própria

Essas relações entre morador e moradia estão em consonância com as interações sociais presentes nos espaços coletivos do próprio conjunto e até mesmo na continua conexão entre a unidade de vizinhança e os espaços da cidade, na formal e na informalidade. É pertinente realizar análises em diferentes escalas de apropriação a fim de associar o desenvolvimento das cidades, as estratégias de inserção urbana, as decisões de projeto e as interações sociais dentro das unidades habitacionais.

Neste artigo, opta-se por realizar pequenas retóricas que permeiam as diversas facetas do planejamento urbano e da arquitetura na análise da produção habitacional inserida em um espaço múltiplo das cidades intermediárias na contemporaneidade, refletidas nas análises comparativas, no diagnóstico da inserção do conjunto habitacional e na observação da situação entre o cotidiano e as decisões projetuais.

\section{CONSIDERAÇÕES FINAIS}

Este artigo trata de uma temática ampla, dinâmica e em constante transformação. Dialogar com a produção da Habitação de Interesse Social associada às conformações urbanas requer um exercício de concatenação complexo e que permeia diferentes conceitos urbanos, arquitetônicos e sociais. Escalas de interação distintas, mas que estão em condição de dependência.

Existe ainda um vasto ambiente de estudo localizado nas cidades intermediárias que precisa ser explorado desde as concepções de projeto, mas principalmente em estudos pós-ocupação que comunicam a estabilidade desses empreendimentos após sua construção. Em decorrência dessas possibilidades de abordagem, o maior problema enfrentado foi tentar não se perder diante da pesquisa e captar de cada subtema o que seria mais importante para a avaliação de uma proposta arquitetônica.

Dessa forma, o Conjunto Major Veneziano e a cidade de Campina Grande refletem a continuidade das práticas de projeto e planejamento urbano dissociadas dos processos de formação e desenvolvimento das cidades, não levando em consideração as dinâmicas sociais, as necessidades dos usuários e as influências dos grandes empreendimentos na morfologia urbana contemporânea.

A continuidade deste pensamento posto em prática empobrece as condições de moradia, isola a sociedade das atividades coletivas cotidianas, higieniza e individualiza os seres dentro dos espaços de vivência, além de gerar cidades urbanamente insustentáveis. Cabe assim, aos diversos agentes transformadores do espaço, 
promover transformações urbanas e projetuais que associem a moradia e a morfologia das pequenas, médias e grandes cidades brasileiras.

Em âmbito internacional, a pesquisa insere a realidade brasileira das cidades intermediárias no que diz respeito à produção de habitação e sua estabilidade no meio urbano. Apresenta a condição construtiva dos conjuntos habitacionais latino-americanos e as dinâmicas presentes nesse sistema coletivo de moradia para a população menos favorecida.

Cabe destacar também que, assim como as dinâmicas do habitar, as inquietações aqui apresentadas, por hora sanadas, não se estagnaram. As análises aqui expostas criaram novas inquietudes acerca do tema da habitação e da morfologia urbana presente nas cidades intermediárias, bem como suas influências no cotidiano dos empreendimentos habitacionais. Muitas discussões, analisadas por um único ponto de vista, ficaram ainda abertas para gerar novos estudos e contribuições para a comunidade acadêmica.

\section{BIBLIOGRAFIA}

BARROS, R. R. M. P. (2008). Habitação Coletiva: a inclusão de conceitos humanizadores no processo de projeto. 2008. Tese (Doutorado em Engenharia Civil) - Faculdade de Engenharia Civil, Arquitetura e Urbanismo, Universidade Estadual de Campinas, Campinas, 2008.

BARCELLOS, Vicente Quintella. (2001). Unidades de Vizinhança: notas sobre a sua origem, desenvolvimento e introdução no Brasil. In: Cadernos eletrônicos da Pós-Graduação em Arquitetura e Urbanismo da UNB (atual Par@noá), v.3, 2001.

BONDUKI, Nabil. (2008). Política Habitacional e inclusão social no Brasil: revisão histórica e novas perspectivas do governo Lula. In: Revista arq.urb, v. 1, n. 05, (2008). Disponível em: www.usjt.br/arq.urb/numero_01/artigo_05_180908.pdf

GHIDINI, Roberto. (2011). A Caminhabilidade: Medida Urbana Sustentável. In: Revista dos Transportes Públicos. Ano 33, 2011. Disponível em <www.mobilize.org.br/midias/pesquisas/a-caminhabilidade-medidaurbana-sustentavel.pdf>.

MELO, Luis Gonzaga. (1986). Habitação popular em Campina Grande. Campina Grande: Universidade Federal da Paraíba. (Dissertação de Mestrado em Sociologia).

ROLNIK, Raquel e NAKANO, Kazuo. (2009). As armadilhas do pacote habitacional. In: Le Monde Diplomatique.2009. Disponível em: <http://www.diplomatique.org.br/artigo.php?id=461> Acesso em: Outubro 2016

SANFELIU, C.B.; TORNÉ, J.M.L.(2004). Miradas a otros espacios urbanos: lãs ciudades intermédias. Geocrítica/Scripta Nova. In: Revista electrónica de geografia y ciências sociales. Barcelona: Universidad de Barcelona, v. 8, n. 165, 15 mai 2004. Disponível em: <www.ub.es/geocrit/sn/sn-165.htm. Acesso em: Outubro 2016>

SERRA, Geraldo. (2006). Pesquisa em Arquitetura e Urbanismo: guia prático para o trabalho de pesquisadores em pós-graduação. EdUSP, 2006.

SILVA, Iranise Alves da. (1986). A política habitacional para as classes de baixa renda de Campina GrandeParaíba. Universidade Federal da Paraíba, 1986. (Dissertação de Mestrado em Economia)

TOPALOV, Christian. (1997). "Do Planejamento a Ecologia: Nascimento de um Novo Paradigma da Ação Sobre a Cidade e o Habitat?." Cadernos do IPPUR (UFRJ/IPPUR) XI (Jan./Dez. 1997): 19-42. 